\title{
De la música de salón a la Semana Santa andaluza: Antonio de la Cruz Quesada (1825-1889) y los orígenes de la marcha procesional granadina
}

\author{
From salon music to Andalusian Holy-week: Antonio \\ de la Cruz Quesada (1825-1889) and the origins of the \\ Granada processional march
}

\section{Da música de salão à Semana Santa andaluza: Antonio de la Cruz Quesada (1825-1889) e as origens da marcha processional de Granada}

\author{
iD Juan Carlos Galiano-Díaz ${ }^{1}$ \\ Universidad de Granada, Granada, España \\ jcgaliano@ugr.es
}

\begin{abstract}
Resumen: El presente trabajo pretende indagar en las primeras marchas procesionales dedicadas a hermandades de Granada, piezas que integraron el paisaje sonoro de la Semana Santa granadina a partir de la Restauración Borbónica. Al efecto, se ha procedido a realizar un estudio y catalogación de diferentes fuentes monumentales localizadas, realizando un análisis cruzado con prensa histórica y literatura científica pertinente sobre el particular. Los resultados obtenidos sugieren que fue Antonio de la Cruz Quesada, compositor conocido por su producción a la música del salón, el pionero en dedicar marchas a hermandades
\end{abstract}

\footnotetext{
1 Graduado Profesional de Música en la especialidad de trompeta Graduado en Historia y Ciencias de la Música y Máster en Patrimonio Musical. Ha participado en numerosos congresos nacionales e internacionales, centrando su investigación en las bandas de música en España y la música procesional andaluza. Cuenta en su haber con numerosos capítulos de libro publicados y ha colaborado con revistas científicas de prestigio como Música Oral del Sur, Revista de Musicología o ll Saggiatore Musicale. En el ámbito internacional, ha realizado una estancia de investigación en el Centro de Sociología y Estética Musical de la Universidad Nova de Lisboa. Asimismo, es miembro del Comité de Redacción de la revista Estudios Bandísticos y de la Comisión de Bandas de Música de la Sociedad Española de Musicología. En la actualidad forma parte del Grupo de Investigación Patrimonio Musical de Andalucía (HUM 263) y es 'Profesor Contratado Predoctoral FPU en el Departamento de Historia y Ciencias de la Música de la Universidad de Granada.
} 
de la ciudad de la Alhambra, constituyendo así el origen de la marcha procesional granadina.

Palabras clave: Antonio de la Cruz Quesada, música procesional, Semana Santa, Granada, Siglo XIX

Abstract: This paper enquires about the first processional marches dedicated to religious brotherhoods of Granada, pieces that integrated the soundscape of the Holy-Week in Granada from the Restoration of the Bourbon Monarchy. For this purpose, a study and cataloging of different localized monumental sources has been conducted, carrying out a crossanalysis with the historical press and pertinent scientific literature on the subject. The results obtained suggest that Antonio de la Cruz Quesada, composer known for his production to salon music, was the pioneer in dedicating marches to religious brotherhoods in the city of the Alhambra, thus constituting the origin of the Granada processional march.

Keywords: Antonio de la Cruz Quesada, processional music, Granada, Holy-week, XIX Century

Resumo: O presente trabalho busca investigar, nas primeiras marchas de procissão dedicadas às irmandades religiosas de Granada, peças que integraram a paisagem sonora da Semana Santa desta cidade a partir da Restauração Bourbon. Para tanto, foi feito um estudo e uma catalogação de diferentes fontes monumentais localizadas, realizando uma análise cruzada com a imprensa histórica e a literatura científica pertinente sobre o assunto. Os resultados obtidos sugerem que Antonio de la Cruz Quesada, compositor conheciùic por sua produção para música de salão, foi pioneiro em dedicar marchas a irmandades religiosas na cidade de Alhambra, constituindo assim a origem da marcha processional de Granada.

Palavras-chave: Antonio de la Cruz Quesada, música processional, Granada, Semana Santa, Século XIX

Submetido em: 19 de março de 2020

Aceito em: 16 de novembro de 2020 
De la música de salón a la Semana Santa andaluza: Antonio de la Cruz Quesada (1825-1889)... Juan Carlos Galiano-Díaz

\section{Introducción}

La Semana Santa es, para los andaluces en general, una de las grandes festividades de la primavera, una celebración de claras reminiscencias barrocas, en la que, además de lo visual, predomina la dimensión tanto sensorial como estético-espacial que, según señala Isidoro Moreno (1982),

supone la exaltación de lo sensible, una verdadera fiesta no para el intelecto sino para todos los sentidos, y a través de éstos para la emoción y el sentimiento. [...] Predomina lo visual pero no en forma de contemplación pasiva, como si de una representación teatral o mero desfile se tratara, sino de espectáculo comunitario en el que hay una continua traslación de los papeles de actoresespectadores (p. 225-227).

Esta festividad constituye un universo cultural y sensorial en el que la música juega un papel protagonista, siendo las marchas procesionales y las saetas "dos manifestaciones musicales que, aunque muy distintas entre sí, tienen en común el haberse gestado en el marco de la religiosidad popular, de forma que hoy día son parte integrante de los desfiles procesionales o las estaciones de penitencia" (BERLANGA FERNÁNDEZ, 2009, p. 13). Más allá de esta presencia, las bandas andaluzas y el repertorio que interpretan en esta festividad religioso-popular se convierten en elementos identitarios de la cultura andaluza (MARTíN RODRÍGUEZ, 2014), sonidos e imágenes que, a su vez, se proyectan en todo el panorama español, europeo e iberoamericano.

Partiendo de lo expuesto, este trabajo tiene como objetivo realizar un estudio y catalogación de las primeras marchas dedicadas a hermandades de la Semana Santa de Granada, cuya autoría corrió a cargo de Antonio de la Cruz Quesada (Granada, 1825- Madrid, 1889). La metodología empleada se inscribe en la investigación musicológica histórica a partir de la consulta, vaciado, catalogación y heurística de diversas fuentes primarias localizadas en E-Mn (Biblioteca Nacional de España), E-Mc (Biblioteca del Real 
De la música de salón a la Semana Santa andaluza: Antonio de la Cruz Quesada (1825-1889)... Juan Carlos Galiano-Díaz

Conservatorio Superior de Música de Madrid) y E-Bbc (Biblioteca de Cataluña), realizando un análisis cruzado con prensa histórica y literatura científica pertinente sobre el particular. Con este fin, se ha diseñado y confeccionado una ficha catalográfica que, con la pretensión de que se adaptara a las necesidades y finalidades del repertorio abordado en este trabajo, ha partido de algunas de las principales aportaciones al campo (MARTíNEZ DEL FRESNO, 1999; IGLESIAS MARTÍNEZ y LOZANO MARTÍNEZ, 2008; MINISTERIO DE CULTURA, 2010). Así, la ficha contiene los siguientes campos: título, subtítulo, número de Opus, publicación/editor, fecha de publicación, número de plancha, lugar de impresión, número de compases, tonalidad, tempo, plantilla instrumental, datos físicos, precio de venta, fuente, observaciones e íncipit² ${ }^{2}$.

\section{Antonio de la Cruz Quesada: un prolífico compositor granadino de la segunda mitad del siglo XIX}

El 16 de mayo de 1865 nacía en Granada Antonio de la Cruz Quesada, compositor, pianistay “maestro de armonía, contrapunto, composición y piano" (CUENCA BENET, 2002, p. 66). Sus primeros pasos en la música los dio bajo la tutela de su tío Joaquín de la Cruz (Granada, s.f.), músico del granadino Teatro del Campillo (GARCÍA AVELLó, 1999). Posteriormente pasó a estudiar solfeo con el pianista José Tamayo (Granada, s.f.) y tras la creación de la Escuela de Música del Liceo Artístico y Literario en 1839 recibió formación en piano, canto y composición de la mano de Bernabé Ruiz de Henares (Churriana de la Vega, 1809- Granada, 1878), primer organista de la Catedral de Granada (BARBERÁ SOLER, 2016).

Según los datos que figuran en el Archivo Universitario de la Universidad de Granada, en el curso académico 1837/1838 Antonio de la Cruz comenzó en la mencionada institución los estudios de Filosofía, en los que obtuvo todos los cursos calificaciones que

2 Para la elaboración del íncipit de las marchas instrumentadas para banda se ha tenido en cuenta el papel de flauta/flautín en re, transportando su melodía para instrumentos afinados en do. 
De la música de salón a la Semana Santa andaluza: Antonio de la Cruz Quesada (1825-1889)... Juan Carlos Galiano-Díaz

oscilan entre el "Notablemente aprovechado" y el "Sobresaliente". Tras concluir Filosofía, inició la carrera de Jurisprudencia, en la que continuó alcanzando óptimas calificaciones hasta el quinto año, tal y como puede observarse en su expediente académico del curso 1844/1845. Sin embargo, en el sexto y último año, correspondiente al curso 1845/1846, se observa una bajada en su rendimiento académico, obteniendo la calificación de "Regular"4. Este descenso no será fruto de la casualidad, tal y como se aborda en el siguiente párrafo. Según figura en los Estatutos del Colegio de Abogados y Lista Oficial del Colegio de Granada, Antonio y sus hermanos Rafael y Diego se inscribieron en el Colegio de Abogados de Granada en 1847, 1849 y 1861, respectivamente, aunque sus nombres se incluyen en el listado de abogados que no ejercieron la profesión (S. N., 1897, p. 12 y 14).

Ese descenso del rendimiento académico al que se hacía alusión con anterioridad puede deberse a que la verdadera vocación de Antonio de la Cruz estaba en la música. En este sentido, hacia mediados de la década de 1840 colaboró en las temporadas de Teatro del Campillo, donde participó en sus producciones operísticas (OLIVER GARCÍA, 2012). Ello le hizo entrar en contacto con la música de Gioachino Rossini (Pésaro, 1792- Passy, 1868), Vincenzo Bellini (Catania, 1801- Puteaux, 1835) o Giuseppe Verdi (Le Roncole, 1813- Milán, 1901). Precisamente, el estilo belcantista junto a la música popular española estarían muy presentes en la producción musical del compositor granadino (BARBERÁ SOLER, 2016). De igual forma, en este periodo el granadino participó activamente en la actividad musical llevada a cabo por el Liceo Artístico y Literario, sociedad en la que tuvo un destacado papel como profesor, pianista y miembro del coro (VARGAS LIÑÁN, 2019).

En este contexto, el 23 de noviembre de 1849 fue estrenada en el Teatro del Campillo La vuelta de Escupe-jumos, primera obra compuesta por Antonio de la Cruz de la que se tiene constancia. Se trata de una zarzuela en un acto con texto del escritor Antonio

\footnotetext{
3 Expediente académico de Antonio de la Cruz Quesada. Fuente: Archivo Universitario de la Universidad de Granada. Signaturas: ES AUG \{l 144\} Principal Caja $0134 / 115$ y ES AUG \{l 145\} Principal Caja 00735/076. 4 lbid.
} 
De la música de salón a la Semana Santa andaluza: Antonio de la Cruz Quesada (1825-1889)... Juan Carlos Galiano-Díaz

Romero Saavedra. La pieza tuvo una gran acogida entre el público, siendo representada en años posteriores a su estreno en Madrid (1850), Barcelona (1851), Zaragoza (1853) o Valencia (1853 y 1859). Del éxito cosechado en su puesta en escena en la capital del Turia se hizo eco el periódico El Granadino (S. N., 1853), tal y como puede leerse a continuación:

Nos escriben de Valencia con fecha 24 del mes anterior, manifestándonos el general desagrado, por un acontecimiento relativo a aquel teatro. Fue el caso que en el día 23 se puso en escena con un éxito brillante la zarzuela de nuestros amigos y paisanos los señores Romero y Cruz, titulada: La vuelta de Escupejumos. Sus bellísimas piezas de canto fueron aplaudidas, y pedida con entusiasmo la repetición de la plegaria de Escupejumos [...] Hoy felicitamos sinceramente por su nuevo triunfo a las entendidas actrices y estudiosos actores, que tomaron parte en la ejecución de aquella zarzuela (p. 2).

En suma, a mediados del siglo XIX Antonio de la Cruz fue uno de los "nudos"5 de la Cuerda Granadina, una tertulia artísticoliteraria que congregó a un grupo de intelectuales del ámbito cultural granadino entre 1850 y 1854, cuya faceta musical ha sido estudiada por Vargas Liñán (2015). En 1850, Antonio de la Cruz sería uno de los primeros miembros de la Cuerda en marchar a Madrid, donde pronto alcanzó gran popularidad gracias a la publicación de sus obras para canto y/o piano en importantes revistas como La Iberia Musical o Gaceta Musical de Madrid (GARCÍA AVELLÓ, 1999), piezas que "adoptó la pudiente sociedad matritense para sus aristocráticos bailes de salón" (BARBERÁ SOLER, 2016). Durante esta etapa inició una estrecha amistad con Francisco Asenjo Barbieri (Madrid, 1823-1894), quien llegó a considerarlo un compositor cursi. Ambos mantuvieron relación epistolar entre 1858 y 1874 durante los periodos que el granadino se encontraba fuera de la capital de España (CASARES RODICIO, 1988, p. 525-528).

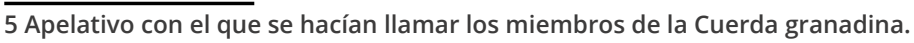


De la música de salón a la Semana Santa andaluza: Antonio de la Cruz Quesada (1825-1889)... Juan Carlos Galiano-Díaz

A pesar de residir en Madrid, a lo largo de la década de 1850 Antonio de la Cruz no perdió la relación con su ciudad natal, según demuestra la publicación de cinco de sus obras para canto y piano en El Álbum granadino, semanario de arte y literatura editado en Granada durante 1856 en el que vieron la luz treinta piezas musicales para salón (VARGAS LIÑÁN, 2005). De igual forma, en 1859 volvió a Granada, manteniendo un estrecho vínculo con la vida musical de esta urbe (VARGAS LIÑÁN, 2015). En 1867 se marchó a Almería, ciudad a la que le dedicó la mazurca Almería, cuya reducción para piano fue editada en Madrid en 1873 por la Casa Editorial de Enrique Villegas (DE LA CRUZ QUESADA, 1873). En el Liceo Artístico y Literario almeriense ejerció como profesor de canto, piano y armonía (VARGAS LIÑÁN, 2019). En el ámbito pedagógico publicó las obras Método completo de solfeo y Teoría de la música (MARTÍN MORENO, 1985). La última etapa de su vida la pasó en Madrid, donde falleció el 25 de septiembre de 1889.

\section{Aproximación a la producción musical de Antonio de la Cruz Quesada}

A lo largo de su trayectoria Antonio de la Cruz compuso más de 200 obras, publicadas en su mayoría por importantes editores como Antonio Romero y Andía, Casimiro Martín, Pablo Martín, Andrés Vidal, José Campo, Benito Zozaya o Nicolás Toledo, entre otros muchos (GOSÁLVEZ LARA, 1995). Debido a ello, puede afirmarse que el granadino fue uno de los compositores de moda en torno a 1880, apareciendo sus obras como reclamo en anuncios de diferentes revistas y periódicos musicales (ALONSO, 1998). Todas sus composiciones fueron catalogadas y ordenadas con número de Opus, lo que significó que el crítico musical Antonio Peña y Goñi (San Sebastián, 1846- Madrid, 1896) lo apodase “Don Opus" (1879a, p. 1). El crítico guipuzcoano le dedicó dos artículos de la serie "Bocetos musicales. Los Musicastros", publicada en Crónica de la Música, donde acometió duramente contra su faceta compositiva, además de reprobar ferozmente la forma de proceder 
De la música de salón a la Semana Santa andaluza: Antonio de la Cruz Quesada (1825-1889)... Juan Carlos Galiano-Díaz

que tenía con los editores para que publicasen sus obras (1879a, p. 1-2; 1879b, p. 1-2).

El grueso de la producción musical de Antonio de la Cruz fue destinado al género del salón. Se trataba de breves piezas para piano o canto y piano como polkas, valses, mazurcas, nocturnos, gavotas, habaneras, canciones españolas e italianas o romanzas, entre otras. De acuerdo con Celsa Alonso (1998):

Su producción en castellano responde a los convencionalismo de un lirismo de salón de pocas ambiciones: armonías muy sencillas, tonalidades fáciles, registros medios, predominio de los ritmos de danza, melodías de corte estrófico, un piano convencional siempre subordinado (acompañamientos típicos del nocturno, la barcarola, el vals, acordes, placados), escaso interés melódico, procedimientos de variación y cambios modales para evitar la monotonía, sin olvidar esporádicas cadencias andalucistas como el nocturno Canto de Amor, la melodía El amanecer, la canción La cantinela del Dauro, la citada Espumita de la Sal [dedicada al tenor Ronconi] o la serenata andaluza A Ella. La melodía El amanecer con versos de Pedro Antonio de Alarcón, es un excelente ejemplo del estilo ecléctico del compositor, una mezcla de pastiche italianizante, ritmo marcial combinado con pinceladas andaluzas [...] y fragmentos declamatorios [...]. Como ejemplo de álbum de salón de espíritu ecléctico cabría destacar el Álbum de Canto de 1875, una colección de obras de gran sencillez que oscila entre el italianismo de Las hadas, el popularismo estereotipado de La cantinera del Dauro (combinación de gamma andaluza y centro tonal) y los ritmos de danza. Se trata en definitiva, de una obra lírica que responde a los requerimientos del salón (p. 468-469).

Sin embargo, a partir de 1875 se observa un acercamiento de Antonio de la Cruz hacia otras agrupaciones instrumentales como la banda de música, gracias a la composición de obras representativas del repertorio bandístico del último tercio del siglo XIX como el pasodoble o la marcha fúnebre. Una de las primeras 
De la música de salón a la Semana Santa andaluza: Antonio de la Cruz Quesada (1825-1889)... Juan Carlos Galiano-Díaz

noticias localizadas que relacionan al granadino con la banda de música data de agosto de 1874, fecha en la que la Banda Municipal de Música de Almería estrenó su mazurca Almería (RAMÍREZ RODRÍGUEZ, 2006, p. 109), que un año antes fue editada en versión para piano por Enrique Villegas (DE LA CRUZ QUESADA, 1873).

Por su parte, al género del pasodoble contribuyó con Los Zapadores y Baleares. El primero de ellos fue dedicado al Cuerpo de Ingenieros Militares y publicado en reducción para piano por los editores Romero y Marzo en 1879. Por su parte, el pasodoble Baleares fue publicado en versión tanto para piano como para banda por José Campo en 1885 (DE LA CRUZ QUESADA, 1885a, 1885b). Cabe resaltar que en la segunda mitad del siglo XIX era habitual que las editoriales musicales publicasen obras concebidas para banda de música en versión reducida para piano con la finalidad de que cada director las instrumentase según las características idiomáticas de su plantilla, o fuesen interpretadas en otros círculos (AYALA HERRERA, 2011, p. 18). Por otra parte, la edición musical para plantilla bandística suponía un mayor coste que para piano, ya que debía incluir tanto la partitura del director como las particellas de las distintas voces de cada uno de los instrumentos, aunque en algunos casos únicamente era editado el guion de director con el fin de abaratar costos.

Ahora bien, si hay un repertorio bandístico al que Antonio de la Cruz contribuyó es, sin lugar a dudas, la marcha fúnebre, que años más tarde derivaría en lo que actualmente se conoce como marcha procesional (GUTIÉRREZ JUAN, 2009). Se desconoce si el compositor granadino fue hermano activo de alguna hermandad religiosa, sin embargo, sí que tuvo relación con la Semana Santa de la ciudad de la Alhambra. Prueba de ello es que en 1867 llevó a Almería desde Granada las partituras del célebre Miserere de Vicente Palacios (Molina de Aragón, 1777- Granada, 1836) para su interpretación en la catedral almeriense durante la Semana Mayor (BARBERÁ SOLER, 2016). 


\section{Las marchas de Antonio de la Cruz: orígenes de la marcha procesional granadina}

Tradicionalmente se ha afirmado que la primera marcha procesional granadina, cuyo nombre se desconoce, fue la dedicada en 1898 por José Moral (Granada?, s.f.- Granada, ca.1940), director de la Banda del Hospicio Provincial de Granada a finales del siglo XIX y principios del siglo XX, a la Hermandad del Santo Entierro (DE LA CHICA, 1999, p. 43). Sin embargo, los primeros acercamientos a este repertorio musical en la capital granadina datan de 1871, año en el que Claudio Lerín (s.l., s.f.- Granada, 1886) compuso una marcha dedicada al Santísimo Sacramento, obra que fue premiada en el Concurso de la Exposición de Agricultura, Industria y Bellas Artes de 1871 (BARBERÁ, 2017). Aunque no se ha localizado ninguna referencia de esta, gracias a su dedicatoria puede afirmarse que se trata de uno de los primeros casos, junto con la marcha triunfal Minerva de José Gabaldá (Vinaroz, 1818- Madrid, 1870), de lo que hoy día se conoce bajo la denominación de "marcha de gloria" (AUTOR, 2020), piezas creadas para su interpretación en los desfiles procesionales que tienen lugar fuera del periodo de Semana Santa o Cuaresma. Respecto a Claudio Lerín se ha constatado que fue director de la Banda del Hospicio Provincial, al menos, desde 1881 hasta su fallecimiento en 1886, año en el que se convocó una oposición para proveer dicha plaza (ROMERO, 1886, p. 1). Precisamente, la primera noticia que se tiene de este al frente de la Banda del Hospicio data de 1881, fecha en la que esta formación acompañó a la procesión del Santo Viático (LEZAGA HERRERA, 1881, p. 2).

No obstante, si hay alguien que contribuyó a la creación de la marcha procesional granadina ese fue Antonio de la Cruz Quesada. La primera marcha que compuso no fue de carácter religioso, sino una marcha real titulada A. S. M. el rey D. Alfonso XII (DE LA CRUZ QUESADA, 1875), dedicada a "El Pacificador" tras su llegada al trono de España en 1874, y publicada en reducción para 
De la música de salón a la Semana Santa andaluza: Antonio de la Cruz Quesada (1825-1889)... Juan Carlos Galiano-Díaz

piano por Pablo Martín en 1875 (Tab. 1). El músico granadino fue fiel defensor de la Restauración borbónica, tal y como demuestra la dedicatoria de varios himnos a Alfonso XII (Madrid, 18571885), quien tras su nombramiento como rey lo invitó a diversas recepciones musicales en palacio a través de Guillermo Morphy y Ferriz de Guzmán “Conde de Morphy” (Madrid, 1936- Baden, 1899) (BARBERÁ SOLER, 2016).

Tabla 1. Ficha catalográfica de A. S. M. el rey D. Alfonso XII

\begin{tabular}{|l|l|}
\hline Título & A. S. M. el rey D. Alfonso XII \\
\hline Subtítulo & marcha real \\
\hline Número de Opus & 107 \\
\hline Publicación/editor & Pablo Martín \\
\hline Fecha de publicación & 1875 \\
\hline Número de plancha & P. M. 3140 \\
\hline Lugar de impresión & Madrid. Calcografía de S. Mascardó \\
\hline Número de compases & 40 \\
\hline Tonalidad & Si bemol mayor \\
\hline Tempo & Maestoso \\
\hline Plantilla instrumental & Piano \\
\hline Datos físicos & Partitura para piano, 2 páginas, 35cm. \\
\hline Precio de venta & 5 reales \\
\hline Fuente & E-Mn (MC/297/74) \\
& E-Bbc (2007-Fol-C 13/72) \\
\hline Observaciones & - \\
\hline Incipit & 2 bóc $\odot ~$ \\
\hline
\end{tabular}

Fuente: Elaboración propia.

Precisamente, fue a partir de Restauración Borbónica de 1874 cuando la Semana Santa granadina comenzó a ver la luz fuera de los templos, siendo la comisión civil y religiosa del Ayuntamiento la encargada de organizar la Procesión del Santo Entierro de Cristo en la tarde del Viernes Santo (DÍAZ GÓMEZ, 2017). Diversas investigaciones han demostrado el auge experimentado por la Semana Mayor granadina en los últimos años del siglo XIX 
De la música de salón a la Semana Santa andaluza: Antonio de la Cruz Quesada (1825-1889)... Juan Carlos Galiano-Díaz

y principios del siglo XX (LÓPEZ GUADALUPE-MUÑOZ \& LÓPEZ GUADALUPE MUÑOZ, 2017; SZMOLKA VIDA, 2017; MONTERO, 2019). Así, el desfile antológico que tuvo lugar el Viernes Santo de 1909 es considerado el punto de partida de la "morfología contemporánea" (DÍAZ GÓMEZ, 2017, p. 82) de la Semana Santa de la ciudad de la Alhambra.

En el ámbito musical fue en 1876 y 1877 cuando Antonio de la Cruz publicó las primeras marchas fúnebres cuya interpretación en los desfiles procesionales se ha podido constatar. Se trata de dos piezas dedicadas a ilustres personajes de la sociedad española: Homenaje a la memoria del ilustre Marqués del Duero y Homenaje a la memoria de Daoiz y Velarde. Ello concuerda con algunos de los títulos de marchas fúnebres que fueron interpretadas en los desfiles procesionales de la Semana Santa de otros puntos de la geografía andaluza a partir de la segunda mitad del siglo XIX (GALIANO-DÍAZ, 2019). Se trata de piezas que no hacían referencia a imágenes de las hermandades sino a hechos dolorosos sufridos por los compositores o a personajes importantes de la vida local o nacional recientemente fallecidos, ya que su interpretación no solo se limitaba a los desfiles procesionales, sino que también formaba parte de la programación de conciertos e incluso eran interpretadas en entierros (OTERO NIETO, 2012).

En relación con lo anterior, la marcha fúnebre Homenaje a la memoria del ilustre Marqués del Duero fue editada en reducción para piano por Antonio Romero (Tab. 2) y dedicada a Manuel Gutiérrez de la Concha e Irigoyen (Córdoba del Tucumán, 1808- Abárzuza, 1874), militar y político español conocido por su título nobiliario de Marqués del Duero, que combatió contra las insurrecciones carlistas (FERNÁNDEZ BASTARRECHE, 2009/2010). Años más tarde, en 1901, sería publicada en versión para banda por la editorial Casa Dotesio, antecesora de Unión Musical Española. A pesar de ello, no se ha localizado su partitura y solamente se tiene constancia de ella gracias a un catálogo publicado en 1901 que contiene un listado de las últimas obras publicadas por Casa Dotesio (S. N., 1901, p. 29). 
De la música de salón a la Semana Santa andaluza: Antonio de la Cruz Quesada (1825-1889)... Juan Carlos Galiano-Díaz

\section{Tabla 2. Ficha catalográfica de Homenaje a la memoria del ilustre Marqués del Duero.}

\begin{tabular}{|c|c|}
\hline Título & Homenage [sic] a la memoria del ilustre Marqués del Duero \\
\hline Subtítulo & marcha fúnebre \\
\hline Número de Opus & 101 \\
\hline Publicación/editor & Antonio Romero y Andía \\
\hline Fecha de publicación & 1876 \\
\hline Número de plancha & A. R. 3653 \\
\hline Lugar de impresión & Madrid. Litografía de Donón. \\
\hline Número de compases & 69 \\
\hline Tonalidad & Re menor \\
\hline Tempo & Maestoso \\
\hline Plantilla instrumental & Piano \\
\hline Datos físicos & Partitura para piano, 3 páginas, $35 \mathrm{~cm}$. \\
\hline Precio de venta & 12 reales \\
\hline Fuente & E-Mn (MP/1273/12) \\
\hline Observaciones & $\begin{array}{l}\text { Cubierta ilustrada firmada por L. Taberner } \\
\text { Una instrumentación para banda fue publicada por Casa Dotesio ca. } 1901\end{array}$ \\
\hline Incipit & 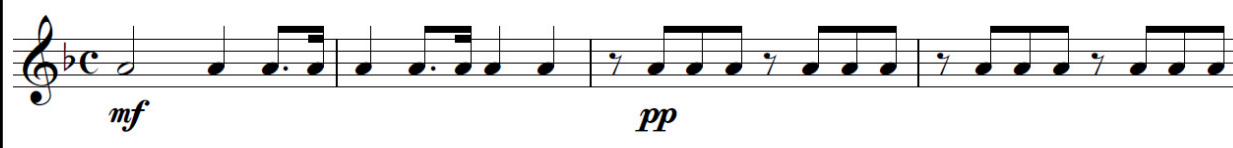 \\
\hline
\end{tabular}

Fuente: elaboración propia

A pesar de no estar dedicada a ninguna hermandad religiosa, gracias a la prensa histórica puede constatarse que fue interpretada no solo en los desfiles procesionales andaluces sino también en los de otras localidades como Cartagena, ciudad muy vinculada con las bandas de música, civiles y militares, desde mediados del siglo XIX (CLARES CLARES, 2005)., Homenaje a la memoria del ilustre Marqués del Duero fue interpretada por la Banda Municipal de Cartagena en los desfiles procesionales de la Semana Santa de 1917, según recoge el diario cartagenero El Porvenir:

Terminemos estos apuntes relatando las marchas fúnebres que han llevado las bandas y orquestas, como también el nombre de los autores de aquellas [...] Municipal: A la memoria del marqués del Duero (A. de la Cruz), Viernes Santo (Tudela), Dolorosa (E. 
De la música de salón a la Semana Santa andaluza: Antonio de la Cruz Quesada (1825-1889)... Juan Carlos Galiano-Díaz

García) y ¡Misericordia! (Estreno, de Julio Hernández). Portman: Perdón y Lamentación (Soutullo), Dolora (de Soutullo y Andreu) y otra de Ponchielli (ACHE, 1917, p. 1).

Por su parte, la marcha fúnebre Homenaje a la memoria de Daoiz y Velarde fue editada en 1877 y dedicada a la memoria de los capitanes Luis Daoiz y Torres (Sevilla, 1767- Madrid, 1808) y Pedro Velarde y Santillán (Muriedas, 1779- Madrid, 1808), oficiales de Artillería del cuartel de Monteleón que se sumaron al levantamiento del 2 de mayo de 1808 contra las tropas francesas. Esta marcha vio la luz en versiones para banda y piano. La reducción para piano fue publicada por los editores Romero y Marzo (Tab. 3) mientras que la partitura de banda lo hizo en el número 2062 de Eco de Marte (Tab. 4) (DE LA CRUZ QUESADA, 1877a, 1877b), principal revista española destinada a la publicación de repertorio bandístico en la segunda mitad del siglo XIX (GALIANO-DÍAZ, 2019). Asimismo, cabe destacar que la instrumentación para banda de Homenaje a la memoria de Daoiz y Velarde no fue realizada por Antonio de la Cruz, sino por el músico mayor Ramón Roig Torné (Lérida, 1849Cartagena, 1907).

Tabla 3. Ficha catalográfica de Homenaje a la memoria de Daoiz y Velarde (piano).

\begin{tabular}{|l|l|}
\hline Título & Homenage [sic] á [sic] /a memoria de Daoiz y Velarde \\
\hline Subtítulo & marcha fúnebre \\
\hline Número de Opus & 124 \\
\hline Publicación/Editor & Romero y Marzo \\
\hline Fecha de publicación & 1877 \\
\hline Número de plancha & R. y M. 5028 \\
\hline Lugar de impresión & Madrid \\
\hline Número de compases & 60 \\
\hline Tonalidad & Do menor \\
\hline Tempo & Maestoso \\
\hline Plantilla & Piano \\
\hline Datos físicos & Partitura para piano, 3 páginas, 35cm. \\
\hline Precio de venta & 6 reales \\
\hline Fuente & E-Mn (MP/1803/5) \\
\hline
\end{tabular}


De la música de salón a la Semana Santa andaluza: Antonio de la Cruz Quesada (1825-1889)... Juan Carlos Galiano-Díaz

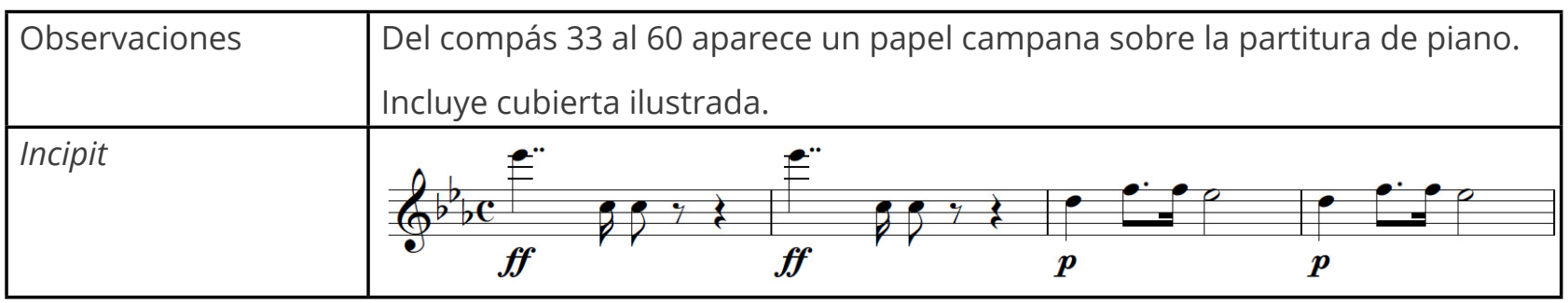

Fuente: Elaboración propia.

Tab. 4. Ficha catalográfica de Homenaje a la memoria de Daoiz y Velarde (banda).

\begin{tabular}{|c|c|}
\hline Título & Homenage [sic] á [sic] la memoria de Daoiz y Velarde \\
\hline Subtítulo & marcha fúnebre \\
\hline Número de Opus & - \\
\hline Publicación/Editor & Revista Eco de Marte, n. ${ }^{\circ} 2062$ \\
\hline Fecha de publicación & 1877 \\
\hline Número de plancha & R. y M. 2062 \\
\hline Lugar de impresión & Madrid \\
\hline Número de compases & 60 \\
\hline Tonalidad & Do menor \\
\hline Tempo & - \\
\hline Plantilla instrumental & $\begin{array}{l}\text { Requinto, flauta y flautín en re, clarinetes (principal, primero, segundo y } \\
\text { tercero), oboe en si bemol, clarinete bajo, saxofón grave en si bemol, saxofón } \\
\text { alto en mi bemol, saxofón bajo en mi bemol, fliscornos, (primero y segundo), } \\
\text { cornetines (primero y segundo), tromba en mi bemol, trompa en mi bemol, } \\
\text { trombones (primero, segundo y tercero) bombardinos (primero y segundo), } \\
\text { barítono [saxhorno], fagotes, contrafagotes, bajos, ruido [caja, bombo y pla- } \\
\text { tillos] y campana. }\end{array}$ \\
\hline Datos físicos & Partitura para banda, 5 páginas, $22 \times 32 \mathrm{~cm}$. \\
\hline Precio de venta & 8 reales \\
\hline Fuente & $\begin{array}{l}\text { E-Mn (MP/129/2). } \\
\text { E-Mc (PI-1109). }\end{array}$ \\
\hline Observaciones & $\begin{array}{l}\text { Instrumentación realizada por Ramón Roig Torné. } \\
\text { Incluye portada de la revista Eco de Marte. } \\
\text { Incluye un "Suplemento al gran catálogo del Eco de Marte" en el que se detalla } \\
\text { un listado de obras de reciente publicación, las bases de la revista y un anun- } \\
\text { cio en el que se indica la autorización de diferentes editoriales para publicar } \\
\text { arreglos de óperas. }\end{array}$ \\
\hline Incipit & 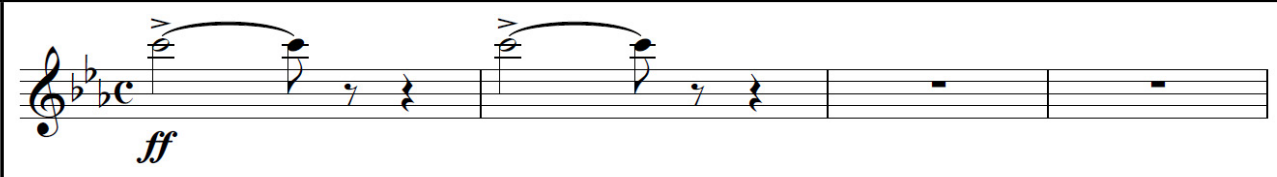 \\
\hline
\end{tabular}

Fuente: Elaboración propia. 
De la música de salón a la Semana Santa andaluza: Antonio de la Cruz Quesada (1825-1889)... Juan Carlos Galiano-Díaz

De la interpretación de Homenaje a la memoria de Daoiz y Velarde en Semana Santa se tiene constancia gracias a la prensa. Concretamente, en Sevilla, donde formó parte del repertorio interpretado por la banda de música del Hospicio Provincial el Viernes Santo de 1904 en su acompañamiento musical a la Hermandad de la Sagrada Mortaja:

\begin{abstract}
La banda de música del Hospicio, que dirige el distinguido músico don Francisco Serra, acompañará en la tarde del Viernes Santo próximo a la cofradía de la Sagrada Mortaja, de Santa Marina. Entre otras marchas fúnebres ejecutará Piedad, Dios mío [de Eduardo López Juarranz?], Daoiz y Velarde [de Antonio de la Cruz], Una lágrima [de Eduardo López Juarranz o Ramón Roig Torné] y Mater Dolorosa [de José María Cavaller] (S. N., 1904, p. 2).
\end{abstract}

Otra formación que interpretó la música de Antonio de la Cruz en la Semana Santa de Sevilla fue la Banda de música del Regimiento de Infantería Granada n. ${ }^{\circ} 34$, con guarnición en la capital hispalense desde 1888. Su repertorio procesional de 1900 contó con la presencia de una marcha fúnebre del compositor granadino que fue interpretada por esta formación en el desfile procesional de las hermandades a las que acompañó a su paso por la plaza de San Francisco:

La banda del regimiento de Granada ha sido contratada para acompañar las siguientes hermandades que han de hacer estación con sus sagradas imágenes en la próxima Semana Santa: la del Cristo de las Aguas, que saldrá el Domingo de Ramos; Cristo de Burgos, el Miércoles Santo; Coronación de Espinas, Jueves Santo y la Esperanza de San Gil, y la de las Tres Caídas el Viernes Santo de madrugada y por la tarde respectivamente. La banda del regimiento de Granada se propone tocar, durante el paso por la plaza de San Francisco, dos marchas fúnebres cuyos autores son don Juan [sic] Antonio de la Cruz y don José Culvist (S. N., 1900, p. 2). 
De la música de salón a la Semana Santa andaluza: Antonio de la Cruz Quesada (1825-1889)... Juan Carlos Galiano-Díaz

Aunque se desconoce de qué marcha se trata, todo hace indicar que la cita se refiere a la marcha fúnebre Homenaje a la memoria de Daoiz y Velarde, pues el músico mayor de la banda del Regimiento de Infantería Granada n. ${ }^{\circ} 34$ en 1900 era Francisco Serra González (Valencia, 1842- Sevilla?, ca.1905), también director de la Banda del Hospicio Provincial de Sevilla entre 1886 y 1907, formación que llevó esta marcha en su repertorio procesional de 1904 , tal y como se ha reflejado en párrafos anteriores.

Los hechos acontecidos en Madrid el 2 de mayo de 1808 sirvieron a Antonio de la Cruz como inspiración para la creación de otra pieza, la marcha nacional A los héroes del 2 de mayo, dedicada a la memoria de todos aquellos que formaron parte de la protesta popular ante la situación de incertidumbre política derivada en España tras el motín de Aranjuez. Fue publicada en 1883 por José Campo en versión tanto para piano (Tab. 5) como para banda (Tab. 6) (DE LA CRUZ QUESADA, 1883a, 1883b). Igual que en el caso de A la memoria de Doaiz y Velarde, la instrumentación para banda no fue realizada por el granadino, sino que corrió a cargo del músico mayor Carlos Pintado (Salamanca, 1842- Madrid, ca. 1895).

Tabla 5. Ficha catalográfica de $A$ los héroes del dos de mayo (piano)

\begin{tabular}{|l|l|}
\hline Título & A los héroes del dos de mayo \\
\hline Subtítulo & marcha nacional \\
\hline Número de Opus & 171 \\
\hline Publicación/Editor & José Campo y Castro \\
\hline Fecha de publicación & 1883 \\
\hline Número de plancha & 246 \\
\hline Lugar de impresión & Madrid \\
\hline Número de compases & 43 \\
\hline Tonalidad & Do menor \\
\hline Tempo & Maestoso \\
\hline Plantilla & Piano \\
\hline Datos físicos & Partitura para piano, 3 páginas, 37cm. \\
\hline Precio de venta & 2 pesetas \\
\hline Fuente & E-Mn (MP/221/4) \\
\hline Observaciones & Incluye cubierta ilustrada \\
\hline
\end{tabular}


De la música de salón a la Semana Santa andaluza: Antonio de la Cruz Quesada (1825-1889)... Juan Carlos Galiano-Díaz

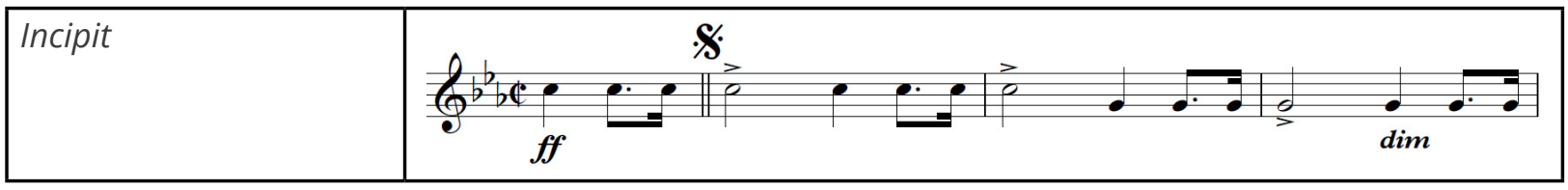

Fuente: Elaboración propia.

Tabla 6. Ficha catalográfica de A los héroes del dos de mayo (banda)

\begin{tabular}{|l|l|}
\hline Título & A los héroes del dos de mayo \\
\hline Subtítulo & marcha nacional \\
\hline Número de Opus & - \\
\hline Publicación/Editor & José Campo y Castro \\
\hline Fecha de publicación & 1883 \\
\hline Número de plancha & J. 248 C. \\
\hline Lugar de impresión & Madrid \\
\hline Número de compases & 43 \\
\hline Tonalidad & Do menor \\
\hline Tempo & Paso lento \\
\hline Plantilla & $\begin{array}{l}\text { Flauta, requinto, clarinetes (primero, segundo y bajo) saxofones en } \\
\text { mi bemol, fliscornos (primero, segundo y bajo), cornetines (primero } \\
\text { y segundo), trombas en mi bemol, trompas en mi bemol, trombones } \\
\text { (primero, segundo, tercero y cuarto), fagotes, bombardinos (primero y } \\
\text { segundo), bajo y batería (caja, bombo y platillos). }\end{array}$ \\
\hline Datos físicos & Partitura para banda, 5 páginas, 27x36cm. \\
\hline Precio de venta & 3 pesetas \\
\hline Fuente & E-Mn (MP/177/17) \\
\hline Notas & Instrumentación de Carlos Pintado \\
\hline Incipit & \begin{tabular}{l} 
\$ \\
\hline
\end{tabular} \\
\hline
\end{tabular}

Fuente: Elaboración propia.

Si bien hasta ahora se han abordado las marchas de Antonio de la Cruz dedicadas a ilustres personalidades fallecidos, va a ser a partir de 1880 cuando los títulos de estas se vinculan directamente con el ámbito de la religiosidad popular. En este sentido, en 1880 fue publicada su primera obra con una clara alusión a la Semana Santa de Granada, la marcha fúnebre Viernes Santo (Tab.7). Fue editada en versión para piano por Antonio Romero, mismo editor que años antes había editado la Marcha fúnebre de Rafael Cebreros (Córdoba, 1851- Sevilla?, 1898) dedicada a la Hermandad 
De la música de salón a la Semana Santa andaluza: Antonio de la Cruz Quesada (1825-1889)... Juan Carlos Galiano-Díaz

de la Quinta Angustia de Sevilla, primera marcha con dedicatoria expresa a una hermandad, de la que se tiene actualmente constancia (CASTROVIEJO LÓPEZ, 2016).

No se ha localizado ninguna fuente que pruebe para qué hermandad fue compuesta Viernes Santo, aunque es más que posible que fuese dedicada a la Hermandad del Santo Entierro de Granada, única en procesionar por las calles de la ciudad de la Alhambra en la tarde del Viernes Santo en el año que la marcha fue publicada. Otro dato que puede confirmar esta hipótesis se encuentra en Córdoba, donde Eduardo Lucena Vallejo (Córdoba, 1849-1893) compuso la marcha Un Recuerdo para el Santo Entierro de la ciudad califal, en cuya portada aparecía: "Al Excmo. Ayuntamiento. Marcha fúnebre Un Recuerdo. Escrita expresamente para la procesión oficial del Viernes Santo del año 1883" (OLAYA MARÍN, 2004).

Tabla 7. Ficha catalográfica de Viernes Santo.

\begin{tabular}{|c|c|}
\hline Título & Viernes Santo \\
\hline Subtítulo & marcha fúnebre \\
\hline Número de Opus & 138 \\
\hline Publicación/Editor & Antonio Romero y Andía \\
\hline Fecha de publicación & 1880 \\
\hline Número de plancha & R. y M. \\
\hline Lugar de impresión & Madrid \\
\hline Número de compases & 69 \\
\hline Tonalidad & Fa menor \\
\hline Tempo & Lento Assai \\
\hline Plantilla & Piano \\
\hline Datos físicos & Partitura para piano, 3 páginas, $37 \mathrm{~cm}$. \\
\hline Precio de venta & 10 reales \\
\hline Fuente & E-Mn (MP/1803/11) \\
\hline Observaciones & $\begin{array}{l}\text { Incluye cubierta ilustrada } \\
\text { Al comienzo de la obra se indica la numeración “N. }{ }^{\circ} 3^{\prime \prime} \text {. }\end{array}$ \\
\hline Incipit & ${ }_{m f}$ \\
\hline
\end{tabular}

Fuente: Elaboración propia. 
De la música de salón a la Semana Santa andaluza: Antonio de la Cruz Quesada (1825-1889)... Juan Carlos Galiano-Díaz

Un año después vio la luz la marcha solemne Al Santísimo Corpus Christi, también publicada en reducción para piano por Antonio Romero (Tab. 8) (DE LA CRUZ QUESADA, 1881). Esta obra constituye la "marcha de gloria" granadina más antigua que se conserva. Para su composición, Antonio de la Cruz se inspiró en una de las festividades religiosas granadinas de mayor popularidad a finales del siglo XIX, la fiesta patronal del Corpus Christi. Ello pone de manifiesto que, a pesar de residir Madrid en la fecha de su creación, el granadino siempre tuvo a Granada presente, demostrando a través de su música que las festividades religiosopopulares están "entre los elementos que tienen la capacidad de resultar símbolos de identificación colectiva con el pueblo, el barrio o la ciudad" (MONTERO, 2019, p. 161).

Tabla 8. Ficha catalográfica de Al Santísimo Corpus Christi.

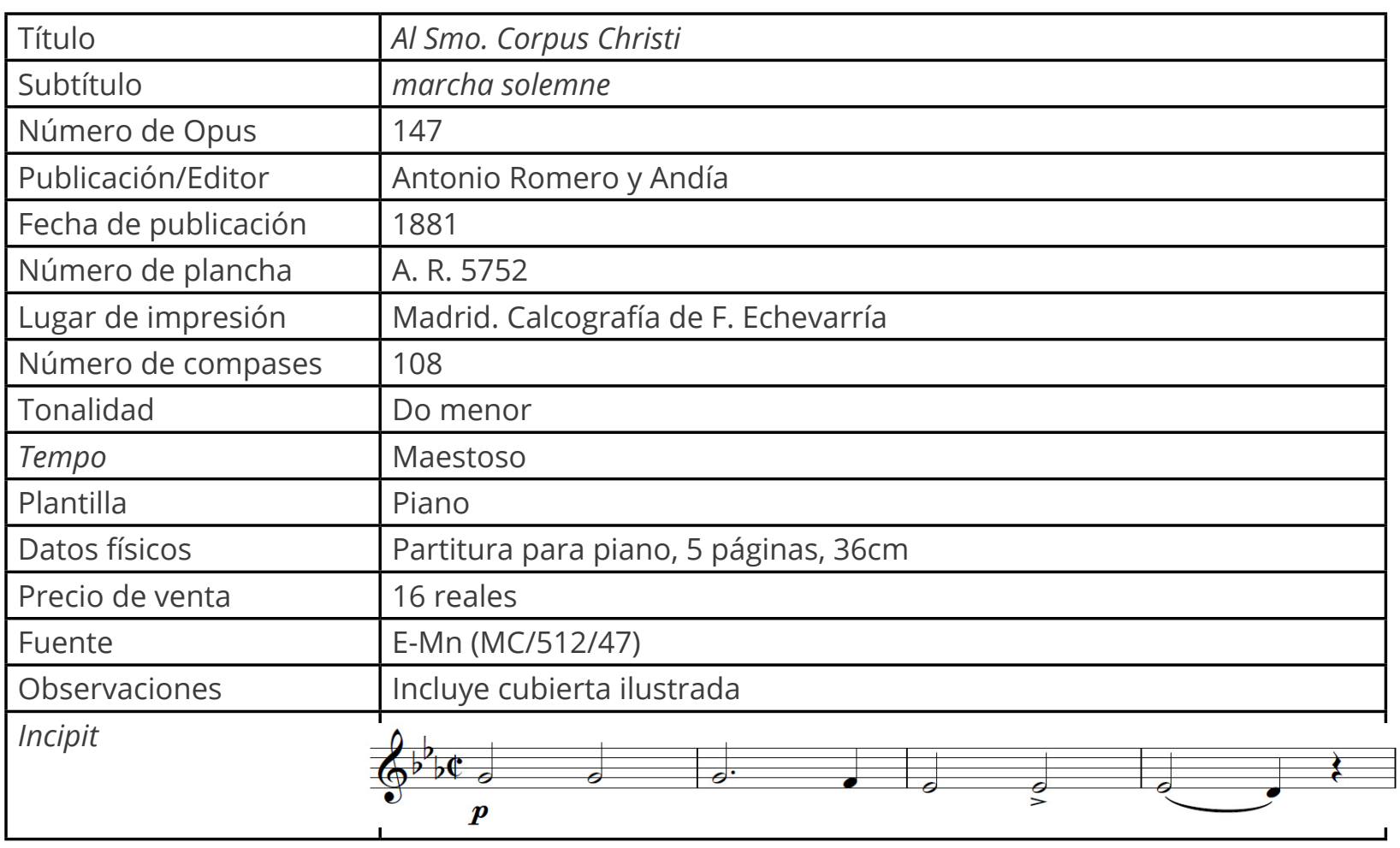

Fuente: Elaboración propia.

La última marcha que Antonio de la Cruz vinculó a una hermandad granadina vio la luz en 1884 y fue dedicada a la Virgen 
De la música de salón a la Semana Santa andaluza: Antonio de la Cruz Quesada (1825-1889)... Juan Carlos Galiano-Díaz

de las Angustias, que en 1887 sería nombrada patrona oficial de Granada por el Papa León XIII. Bajo el título A la Santísima Virgen María bajo la advocación de Ntra. Sra. de las Angustias: marcha solemne, Op. 182, fue publicada en Madrid por José Campo en versión para piano (Tab. 9) (DE LA CRUZ QUESADA, 1884). Aunque no se tienen pruebas fehacientes de ello, posiblemente fue interpretada por la Banda de Zapadores Bomberos y la Charanga del Batallón de Cazadores de Cuba, formaciones que acompañaron musicalmente en estos años a la Virgen de las Angustias en su salida procesional (S. N., 1882, p. 1)6. Por otra parte, a pesar de la fuerte vinculación que mantuvo siempre Antonio de la Cruz con Granada, se desconoce si este tuvo relación con la Hermandad de las Angustias, aunque, según se ha podido constatar en el Archivo de la Hermandad, nunca llegó a ser hermano activo de la misma ${ }^{7}$.

Tabla 9. Ficha catalográfica de A la Santísima Virgen María bajo la advocación de Nuestra Señora de las Angustias

\begin{tabular}{|l|l|}
\hline Título & $\begin{array}{l}\text { A la Santísima Virgen María bajo la advocación de Ntra. Señora de las } \\
\text { Angustias }\end{array}$ \\
\hline Subtítulo & marcha solemne \\
\hline Número de Opus & 182 \\
\hline Publicación/Editor & José Campo \\
\hline Fecha de publicación & 1884 \\
\hline Número de plancha & 265 \\
\hline Lugar de impresión & Madrid \\
\hline Número de compases & 59 \\
\hline Tonalidad & Mi menor \\
\hline Tempo & Maestoso \\
\hline Plantilla & Piano \\
\hline Datos físicos & Partitura de piano, 35cm (3 páginas) \\
\hline Precio de venta & 3 pesetas \\
\hline Fuente & E-Mn (MC/509/11) \\
\hline
\end{tabular}

6 En esta época la Virgen de las Angustias realizó su desfile procesional durante los días de Semana Santa y no en el mes de septiembre, como lo hace en la actualidad. Así, en 1881 procesionó el Domingo de Resurrección, mientras que en 1882 lo hizo en la tarde del Sábado Santo.

7 Libros 57, 58, 63 y 64. Fuente: Archivo de la Muy Antigua, Pontifica, Real e llustre Hermandad Sacramental de Nuestra Señora de las Angustias Patrona de Granada y su Archidiócesis. Sin Signatura. 
De la música de salón a la Semana Santa andaluza: Antonio de la Cruz Quesada (1825-1889)... Juan Carlos Galiano-Díaz

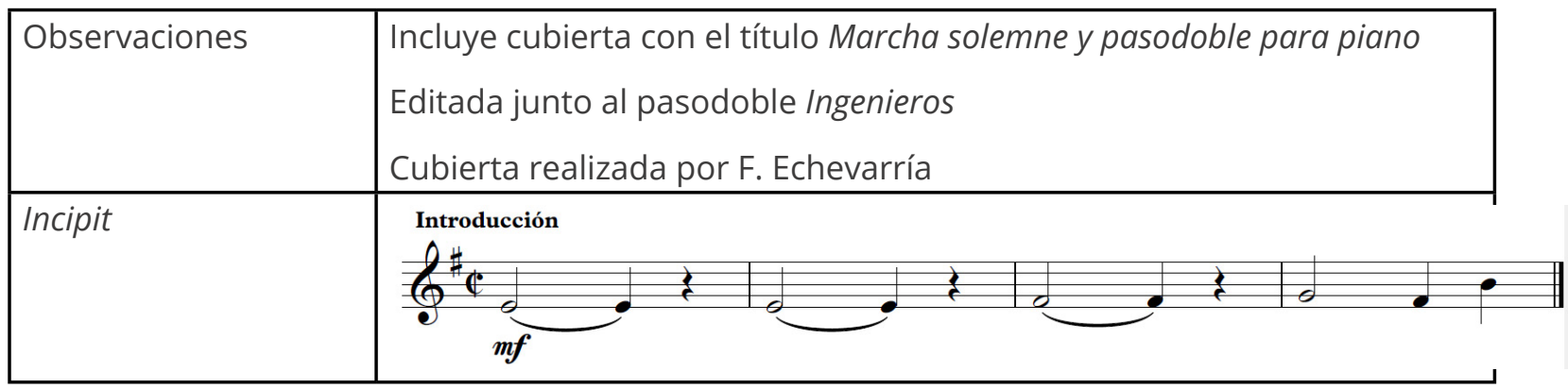

Fuente: Elaboración propia

\section{Conclusiones}

A través del presente texto se ha pretendido arrojar luz en torno a las primeras marchas fúnebres dedicadas a hermandades granadinas en el último tercio del siglo XIX. Tal y como se ha puesto de manifiesto, fue tras la instauración de la Restauración Borbónica de 1874 cuando la Semana Santa de Ganada comenzó a ver la luz más allá de los templos, momento en el que las bandas de música militares y civiles iniciaron su acompañamiento a los desfiles procesionales. Ello conllevó al surgimiento de las primeras marchas dedicadas a hermandades de la ciudad de la Alhambra, cuyo origen había sido tradicionalmente datado en 1898, año en el que vio la luz una marcha dedicada por José Moral a la Hermandad del Santo Entierro (DE LA CHICA ROLDÁN, 1998).

Sin embargo, respondiendo al objetivo marcado al inicio de este trabajo, los resultados obtenidos sugieren que fue Antonio de la Cruz Quesada -compositor granadino que alcanzó gran popularidad en Madrid durante la segunda mitad del siglo XIX gracias a su producción musical destinada al salón-quien dedicó las primeras marchas a hermandades de la ciudad de la Alhambra. En este sentido, se han localizado en E-Mn, E-Mc y E-Bbc un total de siete marchas de su autoría, editadas entre 1875 y 1884, que han sido catalogadas en el presente texto. En términos generales, cabe destacar que cinco de las siete marchas están vinculadas de 
De la música de salón a la Semana Santa andaluza: Antonio de la Cruz Quesada (1825-1889)... Juan Carlos Galiano-Díaz

forma directa o indirecta con la Semana Santa no solo de Granada sino también de otras provincias andaluzas como Sevilla o incluso en la región de Murcia — caso de la ciudad de Cartagena-. Estas marchas resultan, cuando menos, extremadamente reveladoras y sugerentes en lo que a la historia de la marcha procesional en la Andalucía de la segunda mitad del siglo XIX se refiere.

En primer lugar, se ha puesto de manifiesto cómo las primeras marchas fúnebres compuestas por Antonio de la Cruz que se interpretaron en Semana Santa no estaban dedicadas a ninguna hermandad, sino a ilustres personalidades de la historia de España como el militar y político Manuel Gutiérrez de la Concha e Irigoyen "Marqués del Duero", a los capitanes Luis Daoiz y Torres y Pedro Velarde y Santillán. Estas fueron compuestas en 1877 y 1878, respectivamente. De igual forma, aunque no se tienen pruebas fehacientes de ello, es más que probable que la marcha $A$ los héroes del dos de mayo (1883) fuese también interpretada en los desfiles procesionales.

En segundo lugar, se ha constatado que fue en la década de 1880 cuando el granadino publicó las primeras marchas dedicadas a hermandades de la ciudad de las que se tienen noticia: Viernes Santo (1880) y A la Santísima Virgen María bajo la advocación de Ntra. Sra. de las Angustias (1884). Estas fueron dedicadas a las únicas hermandades que procesionaban por las calles de Granada en esta época, la Hermandad del Santo Entierro y la Hermandad de la Virgen de las Angustias. Otra de las festividades vinculadas a la religiosidad popular de Granada en la que Antonio de la Cruz se inspiró fue el Corpus Christi, para la que editó en 1881 la marcha solemne Al Santísimo Corpus Christi.

Finalmente, desde el punto de vista de la edición musical, se hace preciso destacar que todas sus marchas fueron publicadas en versión para piano, siendo también editadas para banda las marchas A la memoria del ilustre Marqués del Duero, Homenaje a la memoria de Daoiz y Velarde y A los héroes del dos de mayo. Precisamente, las instrumentaciones para banda no fueron realizadas por el granadino, sino por músicos mayores del ámbito 
De la música de salón a la Semana Santa andaluza: Antonio de la Cruz Quesada (1825-1889)... Juan Carlos Galiano-Díaz

castrense como Ramón Roig o Carlos Pintado, hecho que nos puede hacer pensar que el compositor granadino poseía escasa formación en lo que a instrumentación se refiere. En este sentido, las ediciones para banda no incluyen número de Opus, a diferencia del resto de obras de su catálogo. Por otra parte, el hecho de que todas las marchas de Antonio de la Cruz fuesen publicadas en Madrid por importantes editores musicales como Pablo Martín, Antonio Romero, José Campo o la revista Eco de Marte dan fe del posible éxito que estas pudieron tener en los repertorios bandísticos de la época. Por otra parte, es más que posible que las marchas de Antonio de la Cruz fuesen compuestas algún año antes de su publicación, tal y como ocurrió en otros ejemplos del repertorio procesional andaluz de la segunda mitad del siglo XIX como la Marcha fúnebre de Rafael Cebreros.

En conclusión, las marchas fúnebres de Antonio de la Cruz encarnan a la perfección la génesis, formación y consolidación de la marcha procesional andaluza en la segunda siglo XIX, uno de los referentes simbólicos del patrimonio musical del sur de España, en el ámbito religioso-popular, que ha ejercido un gran poder de atracción y una expansividad notable a lo largo y ancho del panorama nacional e internacional.

\section{Referencias}

ACHE. De Procesiones. XIV. El Porvenir, Cartagena, p. 1, 7 de abril de 1917.

ALONSO, Celsa. La canción lírica española en el siglo XIX. Madrid: ICCMU, 1998. 555 p.

AYALA HERRERA, Isabel María. Haydn para todos: La transcripción para banda de música del minueto de la Sinfonía no 100 "Militar" por Mariano San Miguel (1879-1935). MAR-Música de Andalucía en la Red, Granada, n. 1, 2011. Disponible en: <https://cutt.ly/9t|DGbb>. Acceso el: 28 de febrero de 2020. 
De la música de salón a la Semana Santa andaluza: Antonio de la Cruz Quesada (1825-1889)... Juan Carlos Galiano-Díaz

BARBERÁ SOLER, José Miguel. Un músico granadino en los salones aristocrácticos de Madrid. Granada Hoy, 10 de octubre de 2016. Disponible en: <https://cutt.ly/xtIDLnd>. Acceso el: 28 de noviembre de 2019.

BARBERÁ SOLER, José Miguel. Las marchas de las procesiones de Granada en el siglo XIX. 11 de abril de 2017. Disponible en: <https:// cutt.ly/7tIDJ7A>. Acceso el: 24 de septiembre de 2019.

BERLANGA FERNÁNDEZ, Miguel Ángel. Introducción En: Berlanga Fernández, Miguel Ángel (Ed.). Polifonías tradicionales y otras músicas de la Semana Santa andaluza. Ciudad Real: Ministerio de Cultura, p. 11-14, 2009.

CASARES RODICIO, Emilio. Francisco Asenjo Barbieri: documentos sobre música española y epistolario (Legado Barbieri), v. II. Madrid: Fundación Banco Exterior, 1988. 1218 p.

CASTROVIEJO LÓPEZ, José Manuel. De bandas y repertorios. La música procesional en Sevilla desde el siglo XIX. Sevilla: Samarcanda, 2016. 506 p.

CLARES CLARES, María Esperanza. Bandas y música en la calle: una visión a través de la prensa en las ciudades de Murcia y Cartagena (1800-1875). Revista de musicología, v. 28, n. 1, 2005, p. 543-562.

CUENCA BENET, Francisco. Galería de músicos andaluces contemporáneos. La Habana: Cultura S.A., 1927. 335 p.

DE LA CHICA, Jorge. Historia de la música procesional granadina. Granada: Comares, 1999. 280 p.

DE LA CRUZ QUESADA, Antonio. Baleares: pasodoble para banda. Madrid: J. Campo, 1885b.

DE LA CRUZ QUESADA, Antonio. A la Santísima Virgen María bajo la advocación de Ntra. Sra. de las Angustias: marcha solemne, op. 182. Madrid: A. Romero, 1884

DE LA CRUZ QUESADA, Antonio. A los héroes del dos de mayo: marcha nacional. Madrid: J. Campo, 1883a. 
De la música de salón a la Semana Santa andaluza: Antonio de la Cruz Quesada (1825-1889)... Juan Carlos Galiano-Díaz

DE LA CRUZ QUESADA, Antonio. A los héroes del dos de mayo: marcha nacional, instrumentación para banda de Carlos Pintado. Madrid: J. Campo, 1883b.

DE LA CRUZ QUESADA, Antonio. A. S. M. el rey D. Alfonso XII: marcha real para piano, Op. 107. Madrid: P. Martín, 1875.

DE LA CRUZ QUESADA, Antonio. AI Smo. Corpus Christi: marcha solemne para piano, Op. 147. Madrid: A. Romero, 1881.

DE LA CRUZ QUESADA, Antonio. Almería: mazurca brillante para piano, Op. 73, Madrid: E. Villegas, 1873.

DE LA CRUZ QUESADA, Antonio. Baleares: pasodoble para piano, Op. 191. Madrid: J. Campo, 1885a.

DE LA CRUZ QUESADA, Antonio. Homenage [sic] a la memoria de Daoiz y Velarde: marcha fúnebre para piano, Op. 124. Madrid: Romero y Marzo, 1877a.

DE LA CRUZ QUESADA, Antonio. Homenage [sic] a la memoria de Daoiz y Velarde: marcha fúnebre, instrumentación para banda de Ramón Roig.Madrid: Eco de Marte, n. 2062, 1877b.

DE LA CRUZ QUESADA, Antonio. Viernes Santo: marcha fúnebre para piano, Op. 124. Madrid: A. Romero, 1880.

DE LA CRUZ QUESADA, Antonio; ROMERO SAAVEDRA, Antonio. La vuelta de Escupe-jumos: zarzuela en un acto. Granada: Imprenta de los Sres. Astudillo y Garrido, 1849.

DÍAZ GÓMEZ, José Antonio. Entre la devoción y el entretenimiento burgués: el papel del Centro Artístico y Literario en la revitalización de la Semana Santa de Granada. En: RODRíGUEZ, María del Amor, PALOMINO RUIZ, Isaac y DÍAZ GÓMEZ, José Antonio (Eds.). Compendio histórico-artístico sobre Semana Santa: Ritos, tradiciones y devociones. Córdoba: Asociación Hurtado Izquierdo, p. 80-105, 2017. FERNÁNDEZ BASTARRECHE, Fernando. Don Manuel Gutiérrez de la Concha: un general liberal en la España de Isabel II. Cilniana, Marbella, n. 22-23, p. 117-126, 2009/2010. 
De la música de salón a la Semana Santa andaluza: Antonio de la Cruz Quesada (1825-1889)... Juan Carlos Galiano-Díaz

GALIANO-DÍAZ, Juan Carlos. Los inicios de la marcha procesional en la Semana Santa andaluza (1856-1898): una revisión histórica. En: RINCÓN, Nicolás y FERREIRO, David (eds.) Bandas de música: contextos interpretativos y repertorios. Granada: Libargo, 2019. p. 149-171.

GARCÍA AVELLÓ, Ramón. Cruz, Antonio de la. En: CASARES RODICIO, Emilio (Dir.). Diccionario de la Música Española e Hispanoamericana, v. 4. Madrid: SGAE, 1999, p. 207-208.

GOSÁLVEZ LARA, Carlos José. La edición musical en España hasta 1936. Madrid: AEDOM, 1995. 215 p.

GUTIÉRREZ JUAN, Francisco Javier. La forma marcha. Sevilla: Abec editores, 2009. 479 p.

IGLESIAS MARTÍNEZ, Nieves; LOZANO MARTÍNEZ, Isabel. La música del siglo XIX: Una herramienta para su descripción bibliográfica. Madrid: Biblioteca Nacional de España, 2008. 512 p.

LEGAZA HERRERA, Ignacio. Miscelánea. Viático. El Defensor de Granada, Granada, p. 2, 21 de mayo de 1881.

LÓPEZ-GUADALUPE MUÑOZ, Miguel Luis; LÓPEZ-GUADALUPE MUÑOZ, Juan Jesús. Historia viva de la Semana Santa de Granada: arte y devoción. Granada: Universidad de Granada, 2017. 536 p.

MARTÍN MORENO, Antonio. Historia de la música andaluza. Sevilla: Editoriales Andaluzas Unidas, 1985. 362 p.

MARTÍN RODRÍGUEZ, Luis Carlos. La imagen de Andalucía en la música cofrade. En: GARCÍA GALLARDO, Francisco José y ARREDONDO PÉREZ, Herminia (Coords.). Andalucía en la música: expresión de comunidad, construcción de identidad. Sevilla: Centro de Estudios Andaluces, p. 205-221, 2014.

MARTÍNEZ DEL FRESNO, Beatriz. (1999). Inventario y catalogación de archivos de bandas civiles asturianas. Actas del $18^{\circ}$ Congreso de la Asociación Internacional de Bibliotecas Musicales, Archivos y Centros de Documentación, San Sebastián. Madrid: AEDOM, 1998. p. 349-363. 
De la música de salón a la Semana Santa andaluza: Antonio de la Cruz Quesada (1825-1889)... Juan Carlos Galiano-Díaz

MINISTERIO DE CULTURA. Reglas de catalogación. Madrid.

Subdirección General de Publicaciones, Información y Documentación, 2010. 626 p.

MONTERO, Manuel. El modelo festivo de Granada a finales del siglo XIX. La celebración de la Toma y de la Semana Santa en los albores de la modernización urbana. Revista del Centro de Estudios Históricos de Granada y su Reino, Granada, n. 31, p. 159-175, 2019.

OLAYA MARÍN, Mateo. Crónica del reestreno de Un Recuerdo. Patrimonio Musical, 6 de diciembre de 2004. Disponible http://www. patrimoniomusical.com/articulo-132. Acceso el: 11 de enero de 2020. OLIVER GARCÍA, José Antonio. El teatro lírico en Granada en el siglo XIX (1800-1868). Tesis doctoral. Departamento de Historia y Ciencias de la Música de la Universidad de Granada, 2012. Granada: UGR, 2012. 593 p. OTERO NIETO, Ignacio. Las marchas procesionales de la Semana Santa de Sevilla. Temas de estética y arte, Sevilla n. 26, p. 239-258, 2012. PEÑA Y GOÑI, Antonio. Bocetos musicales. Los Musicastros II. Don Op. Crónica de la música, Madrid, p. 1-2, 2 de enero de 1879a. PEÑA Y GOÑI, Antonio. Bocetos musicales. Los Musicastros II. Don Op. (Conclusión). Crónica de la música, Madrid, p. 1-2, 9 de enero de 1879b.

RAMÍREZ RODRÍGUEZ, Carmen. El teatro lírico almeriense durante la época de la Restauración. Tesis doctoral. Universidad de Almería, 2006. Almería: UAL, 2006.

ROMERO, Carlos. Unas oposiciones notables. EI Defensor de Granada, Granada, p. 1, 15 de julio de 1886.

S. N. Catálogo general de las obras de música instrumental de los fondos editoriales de Eslava, Fuentes y Asenjo, P. Martín y de Zozaya, publicadas por la Sociedad Anónima Casa Dotesio, editorial de música, única sucesora de las casas Almagro y $C^{a}$, Dotesio, Eslava, Fuentes y Asenjo, P. Martín, Ripalda, Romero y de Zozaya. Madrid: Casa Dotesio, n. 2 bis, 1901. 21 p.

S. N. El Noticiero Sevillano. Sevilla, p. 2, 26 de marzo de 1904. 
De la música de salón a la Semana Santa andaluza: Antonio de la Cruz Quesada (1825-1889)... Juan Carlos Galiano-Díaz

S. N. El Porvenir. Sevilla, p. 2, 6 de marzo de 1900.

S. N. Estatutos del Colegio de Abogados y Lista Oficial del Colegio de Granada. Granada: Imprenta de Indalecio Ventura, 1897.

S. N. Miscelánea. La procesión de la Virgen. El Defensor de Granada, Granada, p. 1, 10 de abril de 1882.

SZMOLKA VIDA, Ignacio. Crisis y transformación del rito de la Semana Santa granadina durante el período de la Restauración. En: RODRÍGUEZ, María del Amor, PALOMINO RUIZ, Isaac y DÍAZ GÓMEZ, José Antonio (Eds.). Compendio histórico-artístico sobre Semana Santa: Ritos, tradiciones y devociones. Córdoba: Asociación Hurtado Izquierdo, p. 354-380, 2017.

VARGAS LIÑÁN, María Belén. La música en la guasona Cuerda granadina: una singular tertulia de mediados del XIX. Granada: Universidad de Granada, 2015. 488 p.

VARGAS LIÑÁN, María Belén. La música en El Álbum Granadino: un periódico intelectual de mediados del siglo XIX. Revista de musicología, Madrid, v. 28, n. 1, p. 426-442, 2005.

VARGAS LIÑÁN, María Belén. Música, sociedades burguesas y periodismo en el siglo XIX: la actividad musical del Liceo de Granada a través de la prensa hasta los inicios de la Restauración. En: QUEIPO GUTIÉRREZ, Carolina y PALACIOS, María (coord.) El asociacionismo musical en España: estudios de caso a través de la prensa. Madrid: Calanda Ediciones Musicales, 2019. p. 255-310.

\section{Agradecimientos}

La presente investigación ha sido llevada a cabo gracias a la concesión de un Contrato Predoctoral de Formación de Profesorado Universitario (FPU16/02001) en el Departamento de Historia y Ciencias de la Música de la Universidad de Granada, otorgado por el Ministerio de Educación, Cultura y Deporte. 